\title{
GDP, Energy and Greenhouse Gases - Some Cross-sectional Evidence
}

\author{
Jan-Erik Lane ${ }^{1}$ \\ ${ }^{1}$ Jan-Erik Lane is an independent scholar who has been full professor at 3 universities and visiting professor at many \\ more. \\ Correspondence: Jan-Erik Lane, an independent scholar who has been full professor at 3 universities and visiting \\ professor at many more. E-mail: janeklane@gmail.com
}

\author{
Received: September 25, 2014 \\ Accepted: October 15, $2014 \quad$ Available online: October 27, 2014 \\ doi:10.11114/aef.v1i2.566 \\ URL: http://dx.doi.org/10.11114/aef.v1i2.566
}

\begin{abstract}
The decreasing ecological capital in the world is a major worry like the possibility of a global spread of a deadly decease like e.g. Ebola. The decline in global ecological capital has to do with the increasing emissions of $\mathrm{CO} 2$ equivalent stuff in the atmosphere, although other factors are also important, like wildlife losses and deforestation as well as desertification. Can economic development be combined with environmental sustainability? On the micro level, many projects show that this is indeed possible. But on the macro level, global emissions of greenhouse gases follow the advancement of country affluence closely. The link is the constantly increasing need for more energy, provided by fossil fuels.
\end{abstract}

Keywords: ecological capital, environmental sustainability, greenhouse gases, energy consumption, economic growth-emission problematic: micro versus macro, Lovelock.

\section{Introduction}

The aim of this short research note is to pin down exactly these macro relationships between economic activity, energy consumption and greenhouse gases, as they hold for the globe today when measured at total levels, or at the global arena.

Economists and environmentalists alike underline that there is in principle no contradiction between economic growth on the one hand and preservation of the environment on the other hand. And they go on to offer many examples of innovations that foster both growth and ecology concerns. Thus, Singapore for instance has spearheaded the development towards economic growth that is also environmentally sustainable. And an entire city in China has been built upon the use of renewable sun energy. Moreover, almost all carmakers have planned for the construction of electricity or hydrogen cars. And many urban sites employ so-called green buses.

This coherence between economic growth and environmental sustainability holds at the micro level in the economy, encompassing lots of interesting and promising projects. However, at the macro level, especially at the global level, matters entirely different, as economic activity in general consumes lots of energy, which results in a constantly increasing emission of greenhouse gases. This global contradiction between economic growth and ecological sustainability, both valued by many people, will most probably be the major headache of the 21 rst century, because there is a limit to the increase in $\mathrm{CO} 2$ equivalent emissions as far as climate change is concerned. Too much global warming may change the basic living conditions on the planet Earth.

\section{Energy Consumption}

British biologist J. Lovelock has stated that Planet Earth runs the incredible risk of destroying the basic conditions for advance life in this century. He is thinking about the danger from the emission of greenhouse gases, filling the Earth's atmosphere with C02 equivalent stuff increasingly (Lovelock, 2007). The rebuttal of Lovelock's dire prediction, shared by several other environmentalists, is the conventional economists' argument that emissions stem from energy consumption, which is actually falling in relation to total production, meaning that the ratio of energy/GDP is declining over time as countries experience economic development - see Diagram 1 for matters in 2011 with some 160 countries.

Diagram 1. Total energy consumption/GDP - GDP of countries: Equation LN Total energy consumption/GDP - Total GDP. Equation: $y=-0.319 x, R 2=0.263$. 


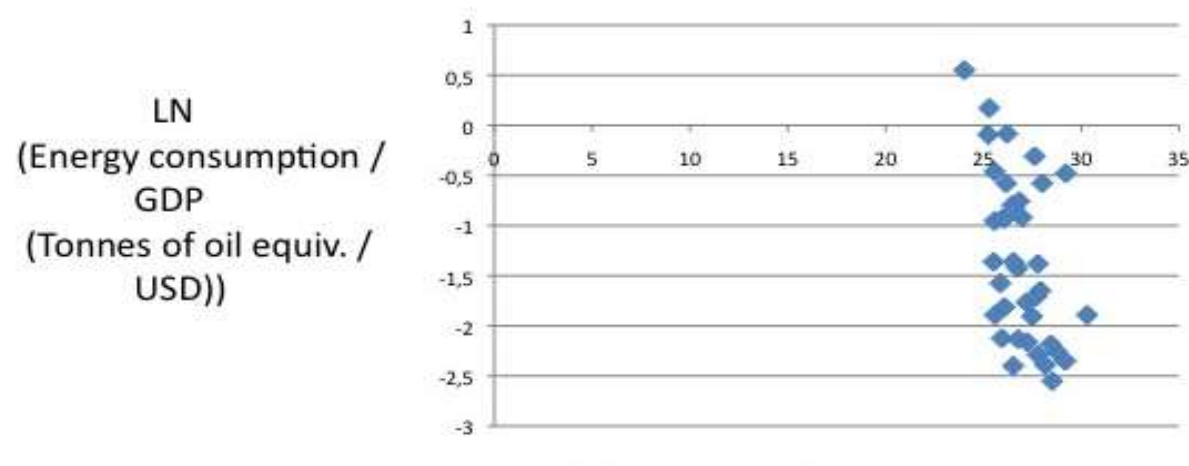

LN (GDP in constant value 2005 US\$)

However, although Diagram 1 shows that the ratio of energy to GDP is declining with growing affluence - a kind of efficiency, the Lovelock warming still holds, because the GDP of the globe is increasing fast. And bigger GDP gives bigger emissions. Every year, energy consumption goes up and with it the emission of greenhouse gases. Since 1979, the global energy consumption has almost doubled and global emission increases have been very strong. Further strong increases in energy consumption are projected (EIA: http://www.eia.gov/cfapps/ipdbproject/IEDIndex3.cfm).

\section{GDP and Greenhouse Gases}

As is well-known, the GDP measures on income or production does not take environmental costs into account. Instead, polluting industries like the airline business, shipping and the car sector contribute considerably to the GDP. It has been argued that the GDP standard indicator should be revised to include the subtraction of ecology costs.

Now, the generation of total income or production for a year comes with the emission of greenhouse gases. Diagram 2 portrays the close connection between GDP and total emission, using LN numbers for most recently available data.

Diagram 2. Total emissions and GDP: Equation: LN GDP - LN GHG Total : $y=0.81 \mathrm{x}, \mathrm{R} 2=0.708$

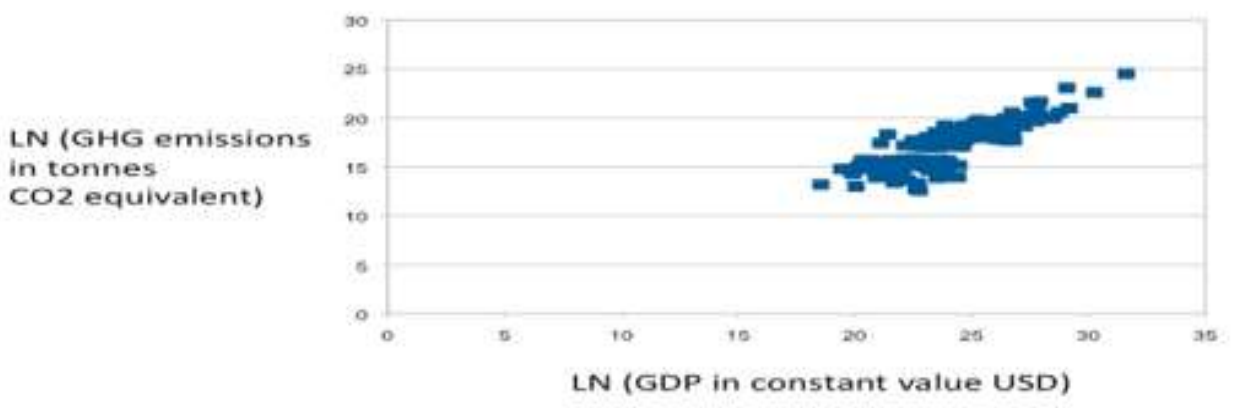

Note: GDP vs. Greenhouse emissions for 158 countries in 2011. Sources: 1. World Bank Open Data, http://data.worldbank.org.2. CAIT WRI 2.0: Climate Data Explorer, World Resources Institute, http://cait2.wri.org

Diagram 2 shows that on the global macro level, the variation in economic development has strong implications for the emission of all kinds of greenhouse gases: the richer and larger a country economy, the more emissions it releases. This finding is, of course, the rationale for the argument that we need another kind of economic growth that builds upon carbon neutral technology. This is no doubt feasible in theory, but in practice we are stuck with the fossil fuel economy. And the destruction of forests and fresh water sources continue.

At global reunions among the politicians and experts, there is much talk about the emissions per capita. Developing countries underline that they tend to display lower emissions per capita than advanced economies. Is this true? Diagram 3 suggests an answer to the question of the distribution of the total greenhouse gases, which is a most policy relevant issue. 
Diagram 3. Emissions per capita and GDP per capita: Equation: LN GDP / CAP - LN GHG / CAP: y=0.52x, $\mathrm{R} 2=0.370$

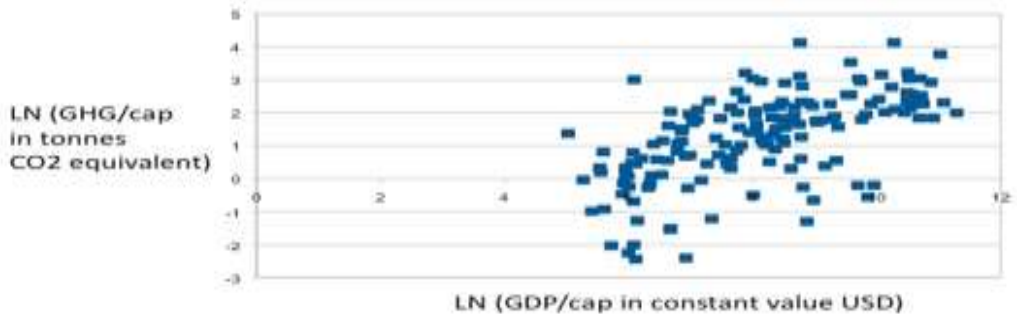

Note: GDP/capita vs. Greenhouse gas (GHG) emissions / capita for 158 countries in 2011. Sources: 1. World Bank Open Data, http://data.worldbank.org. 2. CAIT WRI 2.0: Climate Data Explorer, World Resources Institute, http://cait2.wri.org

The finding, however, suggests strongly that emissions per capita is only weakly associated with GDP per capita. Thus, a few rich countries have rather low emissions, whereas some developing countries have substantial emissions per person. Thus, a global policy for ecological sustainability with regard to emissions control must be the responsibility of all countries on the globe, all people being concerned. It is true that a few rich countries have very high emission per capita (Gulf States, Australia, the US), but most of the emissions originate in the very populous countries in the world, especially in Asia.

Economic development can, I emphasize again, be environmental friendly. Many micro projects have reduced carbon emissions and yet delivered goods and services more efficiently. However, what counts at the macro level is the overall addition and subtractions. Take the example for Singapore that is well aware of the energy-environmental conundrum. Although it must be admitted that Singapore is doing many advanced projects to promote ecological sustainability, it should be pointed out that it is a big hub for air traffic and see shipping, which both result in greenhouse gases. In addition, Singapore has coal fired power stations and consumer huge amounts of electricity (water cleaning, waste treatment, air conditioning in almost all housing and public buildings).

The same contradictory finding applies to the UAE where lots of investments are done in ecologically friendly projects. But the fact remains that $\mathrm{CO} 2$ emissions per capita here are the largest in the world, like Qatar.

To understand the close link between total GDP and total emissions one needs to look at global energy consumption.

Economic activity in all forms consumes directly or indirectly huge amounts of energy. This leads to the emission of greenhouse gases, directly or indirectly. To take a somewhat drastic example: the rapid increase in consumption of meat energy has resulted in an enormous growth of the number of cows in the world, which produce methane that is very conducive to climate change and global warming. Diagram 4 shows the close connection between total GDP and total energy consumption today.

Diagram 4. GDP and energy consumption: LN GDP - LN energy consumption: $y=0.71 x, R 2=0.695$.

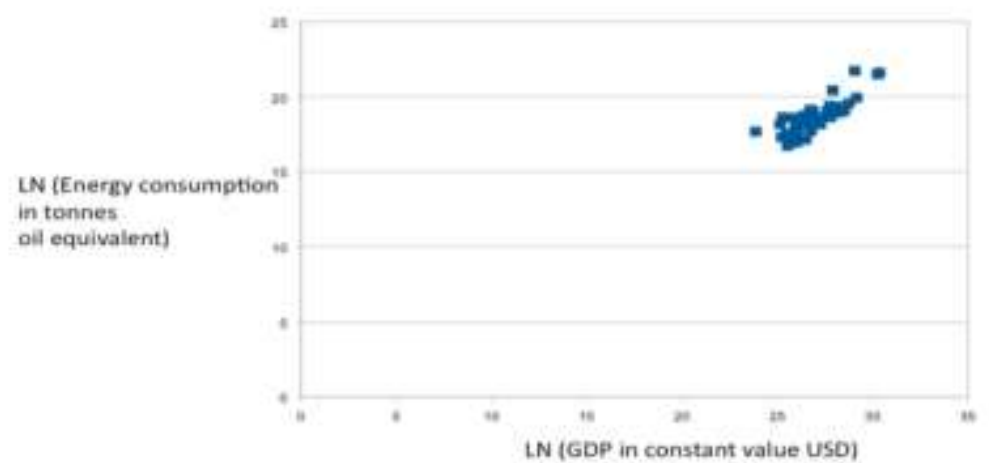


It is also the case that rich countries consume more energy per person than poor countries, as higher levels of affluence require more energy - in general. Again, the situation is paradoxical, as rich countries can invest in environment friendly technology but they also consume more energy for upholding their lifestyle. Diagram 5 has the finding.

Diagram 5. GDP per capita - energy consumption per capita: LN GDP / CAP - LN Energy consumption / CAP: y=0.47 $\mathrm{x}, \mathrm{R} 2=0.64$

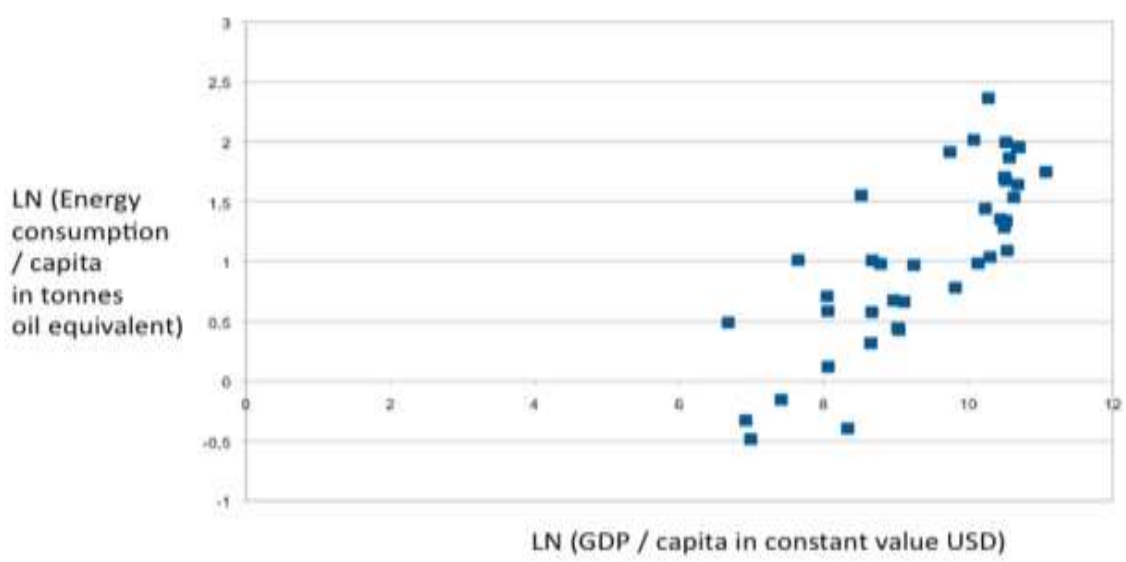

More affluent or luxury life styles are exhibited not only in bigger and stronger cars but also in more heating and air conditioning. Electricity is much needed in affluent countries. If it is not to be produced by nuclear energy, as in Germany, a country mat actually rely more upon coal fired power stations with massive amounts of imports of coal from developing countries, like Colombia with dismal ecological effect.

\section{Undeniable Relevance of Economic Growth}

Economists and politicians emphasize the need for balanced growth on many occasions. Zero economic growth has been pledged by a small group of people, talking about the global limits to growth. They are often rebutted by the argument that growth and environment do not necessarily collide. This is true - at the micro level.

One understands the quest of e.g. France for economic growth, having experienced the misfortunes that a long period of almost zero growth leads to: budget cuts, loss of public service employees, too little investments, reductions in welfare spending, cutting back on culture projects, etc.

Development theory provides a key role to economic growth for the ambition of the Third World to catch-up with the First World. The recent surge in economic growth in for instance the new economic giant countries is looked upon with envy by the member states in the European Union (Table 1).

Table 1. Economic affluence in the 21rst century (LN GDP per capita in constant value 2005 USD)

\begin{tabular}{lccccc}
\hline Year & 2000 & 2003 & 2006 & 2009 & 2013 \\
\hline Euro area & 10,3 & 10,3 & 10,4 & 10,3 & 10,4 \\
European Union & 10,2 & 10,2 & 10,2 & 10,2 & 10,3 \\
Brazil & 8,39 & 8,40 & 8,49 & 8,57 & 8,67 \\
India & 6,36 & 6,47 & 6,68 & 6,85 & 7,06 \\
China & 7,02 & 7,26 & 7,57 & 7,87 & 8,18 \\
United States & 30,1 & 30,1 & 30,2 & 30,2 & 30,3 \\
\hline \multicolumn{4}{c}{ Source: World Bank Open Data, http://data.worldbank.org }
\end{tabular}

\section{Conclusion}

Global ecological sustainability is not enhanced as long as total carbon equivalent emission increase, i.e. augments sharply year in and year out in reality. Two factors increasing greenhouse gases on the macro or global level are world population and economic activity:

Equation I: $\quad$ Total greenhouse gases $=\mathrm{LN} \mathrm{GHG}=0.520 * \mathrm{LN}$ GDP $+0.477 *$ LN Pop, R2=0.76. 
This equation models the global situation today. One can imagine what happens to total greenhouse gases emissions and ecological sustainability when the world population reaches 9 billion and GDP doubles.

The major factor behind the increases year by year in greenhouse gases by some 3 per cent, besides many promising innovations, is the constantly augmenting need for energy. Other factors matter too, it is true, like the cutting or burning down of forests and the acidification of the seas and oceans. We look at the following equations finally:

Equation II. Ln Energy $=0.477 *$ LN Pop $+0.43 *$ LN GDP, R2=0.88.

Again, the increase in energy consumption predictions for the next coming two decades from Energy Information Administration (EIA: Annual Energy Outlook for 2014) mirror the projected growth in world population and the optimistic scenario for economic production or the stylised economic growth rates. I believe the energy factor is the central one factor that should be targeted in global policy decision-making.

The G20 group of states and governments need to do something to promote the use of energy from renewable resources. As they represent almost 80 per cent of global country population, the G20 could embark upon an ecologically sustainable energy policy without either free riding or massive transactions, which have plagued the UN efforts thus far. Changing energy patterns is the only realistic option, as the quest for economic growth is unstoppable.

In this century, much more has to be done to maintain ecological capital. One dimension of ecological capital is to halt the increases in $\mathrm{C} 02$ equivalent emissions, as global warming has dismal effects upon the global environment in general.

\section{References}

Data for GDP, GDP per capita, and population: World Bank Data indicators: http://data.worldbank.org/indicator.

EIA: Energy Outlook for 2014:http://www.eia.gov/forecasts/aeo/

Energy consumption data: Enerdata Global Statistical Yearbook: http://yearbook.enerdata.net

Greenhouse gas emission data: World Resources Institute CAIT2, http://cait2.wri.org.

Lovelock, J. (2007). The Revenge of Gaia: Why the Earth Is Fighting Back — and How We Can Still Save Humanity. Santa Barbara CA: Allen Lane.

\section{(c) $)$ EY}

This work is licensed under a Creative Commons Attribution 3.0 License. 